\title{
Algunas Ideas sobre las Determinaciones Fundamentales del Surgimiento del Trabajo Social como Profesión
}

\begin{abstract}
RESUMEN Este trabajo pretende contribuir a la comprensión del «significado social y político» de nuestra profesión, lo que exige esfuerzos por aprehender los procesos socio-históricos que asisten para su afirmación como práctica profesional particular. Buscamos comprender el surgimiento de nuestra profesión, entendiéndola como una respuesta a circunstancias históricas determinadas, propias del momento del desarrollo del modo de producción capitalista y el tipo especifico de sociedad que le es correspondiente.
\end{abstract}

PALABRAS CLAVES Historia del Trabajo Social - Relaciones Sociales - Capitalismo - Estado

\section{1 - Nociones preliminares}

En momentos de hegemonía de pensamientos débiles, de posibilismo radical, de oportunismo naturalizado, de agudización de los trazos barbarizantes de nuestras sociedades, entendemos imperioso entablar resistencia a partir del estudio riguroso de las producciones teóricas propias de nuestro campo que consideramos como "clásicas del pensamiento crítico" del Trabajo Social en América Latina. Nos estamos refiriendo, particularmente, a las obras de Marilda lamamoto y de José Paulo Netto, ambas, referencias ineludibles para un propósito como el presente. Con este trabajo pretendemos contribuir a la comprensión del "significado social y político" de nuestra profesión, lo que exige esfuerzos por aprehender los procesos socio-históricos que asisten para su afirmación como práctica profesional particular. Buscamos comprender el surgimiento de nuestra profesión, entendiéndola como una respuesta a circunstancias históricas determinadas, propias de determinado momento del desarrollo del modo de producción capitalista y el tipo especifico de sociedad que le es correspondiente. Partimos de la pregunta por las mediaciones que particularizan al Trabajo Social como una especialización del trabajo colectivo (social), en el ámbito 


\section{Ramiro Dulcich}

de las relaciones sociales vigentes (Iamamoto, 1997).

Nuestra preocupación se centra en captar el marco más amplio de determinaciones que definen y dan sentido al Trabajo Social como profesión, esto es, que le otorgan una funcionalidad social al interior del complejo de relaciones sociales propias de la sociedad capitalista. Funcionalidad esta, que no la entendemos de modo determinista, unilateral, al modo de las posiciones "trágicas" de la profesión que devienen en prácticas que se adaptan a lo dado o, en su reverso, en prácticas de abandono de los espacios ocupacionales. Por otro lado, dicha funcionalidad social, tampoco debe ser silenciada desde pensamientos que se pretenden mas allá de la historia real y efectiva, o que ya no le otorgan importancia a la comprensión del surgimiento de nuestra profesión desde una perspectiva de totalidad, esto es, entendiéndola situada en el proceso histórico que la condiciona y dentro del cual adquiere sentido.

En este sentido, el trabajo de analizar la profesión inmersa en el proceso histórico-social más general y mediatizada por la organización capitalista de la sociedad contemporánea, supone, como prerrequisito, el tratamiento y comprensión, lo más rigurosa posible, y -éste ensayo representa apenas un grano de arena en ese desierto- de la "naturaleza" específica del orden social donde se gesta; esa llave abrirá la posibilidad de comprender su "significado" socio-político.

\section{2 - Producción- reproducción de la vida material de la sociedad}

Con base en una concepción materialista de la historia, podemos afirmar que para la existencia de la vida social es preciso, primariamente, que sean producidas las condiciones materiales indispensables para la vida de los individuos. Esto significa el hecho mas o menos obvio de que ciertas necesidades elementales de la vida humana deben ser satisfechas para que podamos hablar de su historia. Así, la existencia del ser social supone, como una condición ineliminable -tal vez la única con este carácter- la producción de los medios de vida que permitan satisfacer las necesidades elementales de los hombres y mujeres; esto es, comer, beber, vestirse, tener habitación, etc.. El proceso por medio del cual se satisfacen las necesidades vitales produce la propia vida material; sin este, no tendría existencia real el ser social, la sociedad.

Por esto, este proceso de producción de la existencia material de la sociedad es el presupuesto ineliminable de toda historia. Desde los comienzos de la humanidad debe ser realizado diariamente por el simple motivo de preservar y reproducir la vida social. Este proceso, indispensable para la vida social, que satisface necesidades y al mismo tiempo genera otras nuevas y más elaboradas, fue caracterizado por Marx y Engels en 1845, como "el primer hecho histórico"1

Esta producción para la satisfacción de necesidades, que crea la existencia material de la vida social, engendra relaciones de cooperación entre los individuos miembros; a través del mismo se procesan interacciones, se crean relaciones sociales. Así, la producción para satisfacer las necesidades crea a la vez nuevas necesidades, y crea también relaciones entre los individuos. Por otra parte, estas necesidades ampliadas crean nuevas formas de relaciones sociales, de cooperación para poder satisfacerlas, al mismo tiempo que el aumento de la población crea nuevas

${ }^{1}$ V. MARX, C.; ENGELS, F. A ideología alema: Feuerbach. São Paulo, Hucitec, 1993. 
necesidades. De esta forma, Marx y Engels (1993) perciben claramente la dialéctica existente en ese momento elemental de la existencia social, el cual se constituye atravesado por las relaciones tensas y conflictivas entre una dinámica productiva movida por las exigencias de satisfacción de las necesidades sociales crecientes (fuerzas productivas sociales), y por las relaciones sociales históricamente establecidas para hacer efectivos dichos procesos sociales productivos. Por esto, puede afirmarse que el desarrollo de las capacidades sociales productivas alcanzadas condiciona y a la vez expresa el estado de desarrollo alcanzado por una determinada sociedad.

Es apenas en este sentido que se entiende la prioridad ontológica del momento económico de la producción en la vida social, el cual demanda formas determinadas de organizar las relaciones sociales para hacerlo efectivo. Con esto no se pretende restar importancia a la subjetividad, a la conciencia, la cultura, la ideología o a la política; se intenta, mas bien, captar las determinaciones efectivas a partir de las cuales se procesa la historia, así como comprender su dinámica y contradicciones. En el caso de la sociedad contemporánea, las relaciones contradictorias establecidas entre la efectivización de una producción material cada vez más socializada (que expresan un determinado grado de desarrollo de las necesidades humanas) y las relaciones sociales particulares entabladas para tal satisfacción, la forma en como esa satisfacción se organiza, en un determinado momento histórico. Esta contradicción se expresa en los términos de una producción cada vez más social y, por esto, cualitativamente más desarrollada, y una apropiación cada vez mas privada y particular de los frutos producidos socialmente.

Por otra parte, la producción de la vida social, considerada en forma ininterrumpida, es lo que llamamos reproducción social. La producción-reproducción de la vida social implica, como vimos, la producción y reproducción de las relaciones sociales nacidas en dicha producción. En este sentido, podemos decir que los hombres hacen su historia, y esta es justamente la historia de la producción reproducción material de la vida social ${ }^{2}$.

\section{3 - División social del trabajo}

La división del trabajo en la sociedad deviene de la necesidad de distribuir la población en los diferentes ámbitos de producción desarrollados para satisfacer las necesidades sociales; así, el modo asumido por tal distribución tiene un papel fundamental en la efectivización del proceso de producción-reproducción de la sociedad. Formas de cooperación, de división social del trabajo y fuerzas productivas sociales se relacionan en una dialéctica donde históricamente el desarrollo de una, a la vez depende y determina la otra. Esto quiere decir que el desarrollo de las fuerzas productivas de una sociedad se encuentra basado y determinado por formas

\footnotetext{
${ }^{2}$ La noción de producción material de la vida no debe comprenderse reducida a la producción de los bienes materiales necesarios para la vida social. Con esta categoría nos estamos refiriendo a la producción de la existencia real, efectiva, objetiva del ser social, que involucra tanto la producción del conjunto de bienes materiales socialmente necesarios para la satisfacción de las necesidades, como también, y por el mismo proceso, la producción de la existencia efectiva, real, del conjunto de relaciones sociales (económicas, de género, ideológicas, políticas, etc.) engendradas y posibilitadas por tal proceso. Entendemos por producción material, junto a Marx, existencia efectiva de lo real, de la totalidad objetiva; en las palabras de Lukács: como síntesis dialéctica de teleología y causalidad.
} 


\section{Ramiro Dulcich}

específicas de organizar la cooperación, la relación entre los individuos miembros.

Con la división social del trabajo ${ }^{3}$, que supone históricamente la división natural del trabajo en la familia y la separación de la población en diferentes grupos opuestos los unos a los otros, se realiza la distribución del trabajo entre dichos grupos que componen la sociedad. Esta distribución está atravesada por relaciones de poder, responde a las luchas entre los diversos grupos sociales por imponerse, y de los resultados históricos de dichas luchas redunda una distribución desigual, cuantitativa y cualitativamente, tanto en lo que se refiere al trabajo, como a los productos del mismo. Así, la división del trabajo, que es división desigual, y su puesta en marcha crea las condiciones históricas para la existencia de la propiedad privada.

En la sociedad capitalista, donde la propiedad privada es el elemento medular que organiza el funcionamiento del sistema y la satisfacción de las necesidades humanas está mediatizada por el mercado -que torna creciente la división social del trabajo-, el desarrollo de las fuerzas productivas se encuentra determinado por los impulsos "ciegos" de la acumulación de capital, lo que hace que las formas de división y organización del trabajo sean tensionadas a ordenarse y reformularse según las exigencias de la acumulación.

Son las propias contradicciones de este modo de producción y las respuestas que históricamente elabora para superar sus crisis, las que provocan continuas reformulaciones en la organización de la producción, en sus diferentes niveles y esferas. Con estas mutaciones permanentes, las modalidades de división del trabajo sufren permanentes alteraciones, y con ellas, se crean, alteran, desaparecen o refuncionalizan, también, actividades, ramas productivas, profesiones, etc.; elementos éstos, partícipes -más o menos directos- de la dinámica (nunca exenta de conflictos socio-políticos) de concentración y centralización del capital.

\section{4 - El capital como relación social predominante}

Nos interesa ahora analizar más específicamente el contenido peculiar de las relaciones sociales propias del modo de producción capitalista; entender la particularidad de las relaciones sociales en las que vivimos, y en las que se gesta nuestra profesión. En este sentido, es común encontrarnos con la idea de que el capital es apenas un objeto, una "cosa", un simple producto, cierta riqueza, etc. Sin embargo, desde una perspectiva crítico-dialéctica, el capital es entendido mucho más allá de eso. Intentaremos aquí aproximarnos al entendimiento del capital como un tipo especifico de relación social que está detrás de esa apariencia "cosificada" necesaria y final que asume el capital. La relación social propia del capital predomina (aunque no es exclusiva) en nuestro tiempo; ella atraviesa y condiciona todo el complejo de relaciones sociales implicadas en el proceso de producción-reproducción de la vida social.

El capital no es una "cosa", sino una relación social particular, que presupone la existencia de determinadas condiciones históricas para poder efectivizarse, siendo sus presupuestos básicos, por un lado, el monopolio de los medios fundamentales de producción de la vida social en manos de un segmento minoritario de la población;

${ }^{3}$ Desde el análisis de Marx y Engels (1993), solo puede pensarse en división del trabajo con la división manual e intelectual del trabajo. Solo a partir de allí, la conciencia puede dejar de ser conciencia de la praxis existente inmediatamente y pasar al mundo de la pura teoría, teología, filosofía, etc. 
por otro lado, y como corolario de lo anterior, la gran mayoría de la población sin acceso a los medios de producción necesarios para reproducirse, o, en otras palabras, sin mas propiedad que su fuerza de trabajo.

Los prerrequisitos históricos del modo de producción capitalista, las determinaciones que lo peculiarizan, deben estar presentes en cada reinicio del ciclo productivo; esto es, son presupuestos necesarios para la reproducción de dicho orden social. De esta forma la reproducción de la sociedad sobre bases capitalistas supone la reposición de estos prerrequisitos, o sea, la reproducción de las condiciones necesarias a la relación social del capital: trabajo asalariado, por un lado, y propiedad de los medios fundamentales de producción en manos de la clase capitalista por otro. En síntesis, la reproducción de esta relación social o la reproducción social organizada sobre bases capitalistas, implica la reproducción del trabajador como no propietario de medios para la satisfacción de sus necesidades más elementales y del capitalista como propietario de los medios fundamentales para la producción material de la vida social.

De lo anterior se desprende que la reproducción social sobre bases capitalistas es un proceso que produce y reproduce esta desigualdad estructural del sistema entre las clases sociales y, con esto, el conflicto que resulta del enfrentamiento de intereses de las mismas. Esto significa que la producción de la vida material de la sociedad, sobre bases capitalistas, es un proceso que recoloca permanentemente las contradicciones que emergen del antagonismo de intereses entre las clases de los propietarios y los no propietarios de medios de producción.

En tales marcos societarios, la finalidad que mueve la dinámica de la producción social no es la satisfacción inmediata de las necesidades humanas sino, antes y más precisamente, la producción para el intercambio en el mercado; esto es, para la venta de mercancías. La finalidad de la producción capitalista no es la producción de "valores de uso" para satisfacer inmediatamente las necesidades de los individuos, sino, más bien, la producción de "valores de cambio" con vistas a su "realización" en el mercado y la consecuente generación de lucros.

La organización de la producción social en el capitalismo esta regida por el afán de ganancias, y la satisfacción de las necesidades se torna menos el fin y más el medio a través del cual se puede cumplir aquella finalidad. El gran motor de la producción social en el capitalismo es la generación de un plus-valor, o sea, de una diferencia de valor entre lo invertido en el inicio de la producción y lo obtenido al final del proceso con la venta del producto ${ }^{4}$. Esta plusvalía, generada en la producción y realizada en la circulación de las mercancías, es lo que convierte al proceso de producción capitalista, también y fundamentalmente, en un proceso de valorización.

De esta forma, en el movimiento de reproducción de la vida social sobre bases capitalistas se recrea el antagonismo de intereses inherentes a las relaciones sociales

\footnotetext{
${ }^{4}$ Es importante destacar aquí que la producción de la plusvalía se efectiviza en el momento de la producción de la mercancía y no en el de la circulación de las mismas (su venta), como creían los economistas clásicos. Fue de Marx el descubrimiento de la plusvalía proviniendo del mundo de la producción, de la relación entre trabajo necesario y trabajo excedente, esto es, la plusvalía como trabajo no remunerado. Hasta entonces se afirmaba que la ganancia provenía del intercambio (en economía el momento de la distribución o circulación), esto es, del hecho de vender por encima del valor (costo de producción) de la mercancía. Marx demuestra genialmente que el lucro no proviene de esa esfera, sino que consiste en el trabajo no remunerado al trabajador, siendo eso lo que llama de plusvalía. Esta se genera allí, cuando el trabajador produce y se realiza en la circulación, cuando la mercancía es vendida y convertida en dinero.
} 


\section{Ramiro Dulcich}

capitalistas, las relaciones y luchas entre las clases fundamentales: la clase de los propietarios y la clase de trabajadores. La reproducción del orden social exige que sean reproducidas las condiciones que propician la explotación de los trabajadores, como también las representaciones que las enmascaran ideológicamente (igualdad jurídica / desigualdad económica).

El capitalismo se configura como un complejo sistema de relaciones sociales que articula, en el tiempo y el espacio preciso, un conjunto de condiciones históricas efectivamente existentes y las ordena según su lógica propia; esto es, la tendencia dominante al interior de ese complejo social, que arrastra al resto de los elementos y tendencias presentes, ordenándolos y otorgándoles sentido en función de su contenido, es la relación social del capital. En ella, la generación de lucros, la producción de plusvalía, se presenta como la finalidad principal que "arrastra", pretende ordenar y condicionar el desarrollo del resto de las determinaciones del proceso histórico. Es, por ende, la relación social predominante. A esto Marx se refería en el primer capítulo de su obra fundamental, El Capital, cuando advertía para el fetichismo del capitalismo, que los hombres se tornan objetos y son dominados y devorados por las cosas.

\section{5 - "Cuestión Social" y Estado ampliado monopolista}

La utilización de la expresión "cuestión social" data de, por lo menos, las primeras décadas del siglo XIX. Con ella, se buscaba designar al fenómeno social más notorio e incómodo que surgía en Europa occidental, como efecto de aquello que luego fue llamado primera revolución industrial: nos referimos al fenómeno del pauperismo ${ }^{5}$.

Este fenómeno social novedoso era sufrido específicamente por la clase trabajadora, y lo peculiar de aquella situación históricamente inédita, consistía en la contradicción de que la pobreza aumentaba en razón directa con el aumento de las riquezas. Con otras palabras, en aquel contexto de consolidación del capitalismo industrial competitivo, el pauperismo de amplias capas de la población trabajadora se producía como proceso concomitante y contradictorio con el aumento de la masa de bienes de consumo disponibles en la sociedad ${ }^{6}$.

Dicha contradicción, propia del orden social capitalista y su régimen de acumulación ${ }^{7}$, no tardará en expresarse en términos de lucha política entre las clases sociales antagónicas. Según Netto (2003), fue precisamente esta profundización del conflicto socio-político, con base en el desarrollo capitalista, y la confirmación efectiva de la posibilidad de subversión del orden burgués, lo que hará que al pauperismo se lo empiece a llamar "cuestión social". Se trataría, entonces, de ocultar las relaciones orgánicas existentes entre acumulación capitalista y producción del pauperismo. Las comillas en la expresión pretenden señalizar este intento de enmascaramiento su contenido.

\footnotetext{
${ }^{5}$ v. NETTO, J. P. Marxismo Impenitente. Contribuição a historia das idéias marxistas. São Paulo, Cortez, 2003. ${ }^{6}$ Idem.

${ }^{7}$ El análisis marxiano de la Ley general de la acumulación capitalista, incluido en el Capitulo XXIII del libro I de El Capital de 1867, revela la anatomía de la «cuestión social»; su carácter de corolario necesario del desarrollo capitalista (Netto, 2003)
} 


\section{$\mathrm{A}\lrcorner \exists\lrcorner$ ЯЯА АЯ口эТ}

"El desarrollo capitalista produce necesariamente la 'cuestión social' diferentes fases capitalistas producen diferentes expresiones de la 'cuestión social' (...) El análisis de conjunto que Marx ofrece en El Capital revela brillantemente que la 'cuestión social' está básicamente determinada por el trazo propio y peculiar de la relación capital / trabajo - la explotación. Sin embargo, la explotación apenas remite a la determinación molecular de la 'cuestión social' (...) El análisis marxiano permite situar con radicalidad histórica la 'cuestión social', esto es, distinguirla de las expresiones sociales derivadas de la escasez en las sociedades que precedieron al orden burgués"8.

De acuerdo con Netto (2003), con la difusión de la expresión "cuestión social" se busca naturalizar, des-economizar y despolitizar las causas estructurales del conflicto social del cual la "cuestión social" es expresión; conflicto éste que está en la base de la lucha de clases. Así, con la "cuestión social" naturalizada, se legitiman propuestas de "enfrentamiento" basadas en acciones moralizadoras. La concepción que allí subyace es una que busca combatir las manifestaciones de la "cuestión social" sin tocar los fundamentos de la sociedad burguesa.

Como ya fue observado, "cuestión social" no es sinónimo de contradicción capital/trabajo, por más que esta última sea su médula; de la misma forma, la relación entre pobreza o pauperismo y "cuestión social" no se procesa sin mediaciones, o sea, no es directa.

Tomando el aporte de Potyara Pereira (en: Borgianni; Guerra; Montano, 2003), la autora nos plantea que la expresión "cuestión social" supone/exige una elaboración política de las necesidades o carencias producidas por la lógica objetiva de la acumulación capitalista; esto es, supone la transformación de necesidades en "cuestiones". Con otras palabras, supone un proceso de elaboración política de las necesidades sociales, de politización de las mismas; supone su comprensión y voluntad de superación. Sin esto no podría existir una "cuestión social", más bien lo que existiría seria una "cuestión social" en estado latente, potencial. Desde este entendimiento, la "cuestión social" más que un resultado directo de la acumulación del capital, es el conflicto político determinado por la elaboración conciente de esas contradicciones ${ }^{9}$.

Por otra parte, en necesario incorporar al análisis una mediación fundamental, que juega un papel extremadamente importante en la producción y reproducción de las condiciones necesarias al funcionamiento del orden social particularizado por el modo de producción capitalista: nos referimos al papel del Estado y sus modalidades de intervención social, muy especialmente en lo que se refiere al enfrentamiento de la "cuestión social", tanto en tiempos históricos donde ésta se manifiesta como tal, para usar la idea de Pereira, como en aquellos momentos donde se encuentra en estado "latente".

\footnotetext{
${ }^{8}$ Netto en: BORGIANNI E.; GUERRA Y.; MONTAÑO C. (Orgs.). Servicio Social Critico: Hacia la construcción del nuevo proyecto ético-político profesional. São Paulo, Cortes Editora, 2003, pp. 63-64.

${ }^{9}$ Para la autora, la falta de fuerzas sociales y políticas con presión efectiva para incorporar en la agenda publica los grandes problemas sociales, buscando su solución, determinan que hoy no tengamos enfrente propiamente una «cuestión social» explícita, sino una incómoda y complicada «cuestión social» latente, cuya explícitación se convierte en el principal desafío de las fuerzas progresistas. (Pereira en: Borgianni; Guerra; Montaño, 2003).
} 


\section{Ramiro Dulcich}

El Estado, en la sociedad específicamente capitalista, es una institución social que tiene en un primer momento una finalidad que se restringe a garantizar -en el sentido fuerte del término- el funcionamiento del orden social. A través del mismo se intenta "resolver" -regular- el conflicto producido por el antagonismo de intereses individuales y colectivos, derivados del modo específico de organización de la sociedad. Para tanto, el Estado toma la apariencia de ser una instancia suprahistórica, neutral, arbitro; una fuerza, preferiblemente legitimada, ocupada en brindar y preservar las garantías del orden social y arbitrar su buen funcionamiento.

Este Estado, históricamente situado, será el espacio privilegiado desde donde se intentará abordar los conflictos políticos que tienen por base la lucha de clases. En la medida que el capitalismo se va profundizando, y con él sus contradicciones; en la medida en que la lucha de clases se profundiza -donde una expresión de ello es la organización política de la clase subalterna-, se hace necesario la creación de instrumentos cada vez más sofisticados para el enfrentamiento de la politización de la "cuestión social". Llegado un determinado momento, se torna necesario, para la clase dominante, crear un tipo de intervención estatal que podríamos llamar también de "regulación social", que tiene por función promover el desarrollo económico de un determinado país o región e intervenir en las desigualdades sociales para evitar que éstas se traduzcan en luchas políticas desestabilizadoras del orden social.

Para la existencia de esta modalidad particular (reguladora-reformadora) asumida por el Estado, son indispensables ciertas condiciones históricas, que podrían resumirse, según $\mathrm{H}$. Abreu, en: a) una sociedad nacional ordenada sobre bases capitalistas; b) un Estado que ejerza su jurisdicción política para garantizar la reproducción de las relaciones sociales; c) el desarrollo de un sentimiento éticopolítico contrario; d) el desarrollo de estrategias y teorías reformistas; e) la producción de un excedente económico creciente que permita una distribución mas profunda, sin herir el funcionamiento del sistema (Abreu en: Borgianni; Guerra; Montaño, 2003).

Recién con la asociación del capital financiero con el industrial, que caracteriza el pasaje del capitalismo competitivo al capitalismo monopolista o imperialismo, en las tres últimas décadas del siglo XIX y las primeras del siglo XX, que produce una enorme concentración de capitales que viabilizan la segunda revolución industrial, se crean las condiciones históricas que permiten una nueva intervención estatal, de naturaleza cualitativamente distinta ${ }^{10}$. Articulado con esto, se encuentra la elaboración de teorías reformadoras del capitalismo y del Estado, que le otorgan a éste último otra funcionalidad mucho más orgánica al sistema, más compleja y sofisticada. Esto permite la emergencia de un tipo peculiar de Estado con un tipo especial de intervención en la sociedad, que abre la posibilidad para que los trabajadores anclen algunas de sus reivindicaciones como conquistas en la profundidad de dicho Estado.

En síntesis, el conjunto de transformaciones procesadas en la coyuntura

\footnotetext{
${ }^{10}$ Desde finales del siglo XIX, y como respuesta a la crisis económica, el capitalismo inicia su segunda revolución industrial. Esta consiste fundamentalmente en la sustitución de la máquina a vapor por las eléctricas o las movidas a combustión; la creación de la radio-comunicación, la electrónica, la aerodinámica, etc. Con base en la «línea de montaje se desarrolla la producción en masa para un consumo masivo. Se producen así, ganancias crecientes de productividad y una gran expansión del excedente económico» (Abreu en: Borgianni; Guerra; Montano, 2003). Esta nueva organización del capitalismo, esa coyuntura histórica, permitirá efectuar ciertos niveles de redistribución de la riqueza, aunque por un tiempo bien reducido y no sin crisis, amortiguando las luchas de clases e intentando integrarlas orgánicamente al cuerpo institucional estatal.
} 
histórica marcada por la entrada del capitalismo en su fase monopolista ${ }^{11}$, permite lo que, pensando con Gramsci, podría llamarse de "ampliación del Estado", donde se transforman y amplían tanto sus bases de representación política, como también sus funciones económico-sociales. Nos ocuparemos un poco mas profundamente de este Estado particular de la fase monopolista del capitalismo y la peculiaridad de su intervención en la sociedad y, específicamente, ante la "cuestión social".

No obstante, la activación de estas contra-tendencias que caracterizan la entrada del capitalismo en su fase monopolista, no significa que puedan eliminarse sus contradicciones inherentes. Por el contrario, como explícita Netto (1992), la "solución monopolista" arrastra consigo los conflictos inherentes al orden del capital; el capitalismo, en su "edad monopólica", repone sobre nuevas bases las contradicciones de la acumulación y valorización del capital. Es por esto, fundamentalmente, que precisa crear mecanismos de intervención extra-económicos que le permitan funcionar con relativa estabilidad. De esta exigencia deriva la refuncionalización y el redimensionamiento de su espacio de intervención en lo social, o extra-económico por excelencia: el Estado.

Sin embargo, es bueno aclarar que la intervención del Estado está lejos de originarse en esta fase; por el contrario, el Estado siempre intervino en el capitalismo. Primeramente, lo hizo limitándose a garantizar las condiciones externas de la producción, solo superando muy ocasionalmente este límite; por esto, su intervención sobre los conflictos emergentes del movimiento contradictorio del orden capitalista, léase la "cuestión social", se caracteriza en ese momento por ser a-sistemática, episódica y emergencial.

Contrariamente, en la fase monopolista del capitalismo, el Estado, además de preservar las condiciones externas de la producción, incide en la organización de la dinámica económica desde adentro ${ }^{12}$; y lo hace de forma continua y sistemática (Netto, 1992). Ahora, el eje de su intervención, como fue ligeramente esbozado arriba, pasa por garantizar un nivel adecuado de la tasa de ganancia del capital ${ }^{13}$. La refuncionalización del Estado en el contexto del capitalismo monopolista se explica por la agudización de las dificultades de reproducción del capital; éste, ahora, exige una estructuración más sutil, menos espontánea, más profunda y abarcativa.

En el capitalismo monopolista, tanto por el refuerzo de las exigencias de la acumulación como por la consolidación política de los trabajadores y su proyecto

\footnotetext{
${ }^{11}$ El trazo que caracteriza principalmente al capitalismo en su fase monopolista tiene que ver con que la forma de organización de la vida social se encuentra deliberadamente destinada a garantizar el nivel de las ganancias capitalistas a través del control de los mercados (Netto, 1992). La organización monopólica se configura como una contra-tendencia para contrarrestar el aumento de la composición orgánica del capital, esto es, para preservar y aumentar la tasa de ganancia (Netto; citado en: Mandel, 1998).

${ }^{12}$ En el capitalismo competitivo, la «cuestión social» era objeto de intervención estatal en la medida en que la conflictividad de la movilización de los trabajadores amenazaba el orden social, o, al límite, se veía amenazada la afluencia de fuerza de trabajo al mercado. De una u otra forma, la intervención estatal se presenta allí como una intervención desde el exterior de la producción, no está internalizada por el funcionamiento capitalista; no están creadas todavía las condiciones que hacen indispensable una intervención estatal en lo social más orgánica al funcionamiento del sistema.

${ }^{13}$ La reposición de las contradicciones propias de la acumulación y valorización del capital en la «edad monopolista» del capitalismo hace que éstas se presenten más agudizadas y violentas. Por esto, el orden capitalista debe reconfigurarse permanentemente para dar respuestas a los conflictos que su desarrollo genera; se crean así, diversos mecanismos económicos, ideológicos y políticos que, activados al interior del todo social, funcionan como contra-tendencias a las tendencias críticas del capital. Estas respuestas, por la agudización de las contradicciones y complejos de problemas, se tornan cada vez más sofisticadas.
} 


\section{Ramiro Dulcich}

de clase, el sistema precisa de nuevos mecanismo para reproducirse con un mínimo de estabilidad; esto es, para garantizar un funcionamiento adecuado de la tasa de ganancia, el orden social precisa recrear su organización estructural en función de lograr cierta legitimidad política. En este camino, el capitalismo en su fase imperialista internaliza la "cuestión social" y pasa a tratarla de forma sistemática y planeada a través de diversos dispositivos asistenciales y servicios, diseñados y ejecutados por agentes específicos que tienen por función responder eficazmente a sus múltiples manifestaciones o refracciones.

En su fase imperialista, el capitalismo tiende a ordenar de tal forma la vida social que ningún intersticio de la misma - tanto la vida pública, como el ámbito de lo privado- quede por fuera de su influencia (Netto, 1992) La tendencia manipuladora que le es propia, desborda el terreno estricto del espacio de producción (la fábrica, la empresa, etc.) y pasa a controlar la circulación, el consumo, produciendo una "inducción comportamental" que penetra la totalidad de la existencia de los individuos. De esta forma, es la propia cotidianeidad la que pasa a ser administrada ${ }^{14}$, regulada.

\section{6 - El Trabajo Social}

Con respecto a la génesis del Trabajo Social no podemos reducirla a una alusión general a la existencia de la "cuestión social", como si fuera un efecto de ésta. Es preciso particularizar la emergencia de la profesión en el contexto histórico del tránsito del capitalismo competitivo al monopólico. Es sólo con este cambio de fase del capitalismo, que expresa un punto más alto en su maduración, que se presentan las condiciones históricas que hacen posible una ampliación y complejización de los sistemas de mediaciones que garantizan y regulan su funcionamiento (Netto, 1992).

En ese marco histórico, con su determinado modo de división social del trabajo, correspondiente a determinada fase de desarrollo del orden social capitalista, pretendemos situar a nuestra profesión. Proponemos pensarla como una actividad profesionalizada que participa en el complejo proceso de producción y reproducción de las relaciones sociales y cuya emergencia histórica responde a la necesidad de dar respuesta a determinadas necesidades que hacen al "buen" funcionamiento del orden social.

Entendemos a la profesión de Trabajo Social, junto a lamamoto (1997), como una especialización del trabajo colectivo dentro de la división social del trabajo, peculiar de la sociedad industrial; como una actividad profesional que participa en el proceso de reproducción de las contradictorias relaciones entre las clases sociales. Esto es, el Trabajo Social como profesión, esta inmerso en la dinámica contradictoria de la sociedad capitalista; es determinado y, a la vez, determina otros procesos históricos sociales; participa de la reproducción de la vida social desde un lugar y con una funcionalidad determinada; es una profesión que actúa, que interviene en esa dinámica conflictiva del orden capitalista construyendo condiciones necesarias para su reproducción. En las palabras de la autora:

\footnotetext{
${ }^{14}$ De acuerdo con Netto, lo privado no desaparece sino que se metamorfosea, producto del ingreso de la organización monopólica en ese ámbito. Así, la mercantilización universal de las relaciones sociales cobra nuevo impulso por medio de los servicios que se crean e invaden lo privado.
} 


\section{$\mathrm{A}\lrcorner \exists\lrcorner$ ЯА}

"El desarrollo de las fuerzas productivas y las relaciones engendradas en ese proceso, determinan nuevas necesidades y conflictos que pasan a exigir profesionales especialmente calificados para su atención. La 'cuestión social' se torna la base de justificación de ese tipo de profesional calificado (...) ésta no es otra cosa que la expresión condensada del proceso de formación y desarrollo de la clase obrera y su ingreso en el escenario político, exigiendo su reconocimiento político. Es la expresión de la contradicción entre proletariado y burguesía potenciado, que pasa a exigir otro tipo de intervención, más allá de la caridad y la represión"15.

El pasaje del capitalismo competitivo al monopolista, con sus procesos de refuncionalización económico-políticos correlativos, no se reduce al reforzamiento del orden capitalista, sin bien allí se situó la tendencia predominante históricamente; o sea, dicho proceso no sólo se efectúa en medio de grandes conflictos sociales y políticos, sino que, además, no logra resolver duraderamente sus contradicciones. Queremos decir con esto que se constituye como un proceso contradictorio que se aleja de cualquier unilateralidad; esto es, no representa apenas una victoria del capital sobre los trabajadores -y si lo es, debe ser entendida sólo en forma parcial-, puesto que estos últimos logran materializar importantes conquistas en el seno del Estado; pero y fundamentalmente implica una superación de las contradicciones que en aquel momento estaban poniendo en riesgo la continuidad del orden social y, al mismo tiempo, representa una reposición potenciada de esas mismas contradicciones que no han desaparecido.

Como fue esbozado más arriba, la edad monopolista del capitalismo repone sobre nuevas bases sus contradicciones inherentes, y una de las manifestaciones más interesantes de esto se expresa en el proceso contradictorio por medio del cual el Estado, al buscar legitimidad política para el orden a través del juego democrático, se torna permeable a las demandas de las clases subalternas, las cuales, algunas veces, logran incorporar en él sus intereses y reivindicaciones inmediatas (lamamoto, 1997); esto significa que pueden materializar en su interior cierto grado de fuerza política en función de sus intereses ${ }^{16}$.

Con su intervención, por su posición y su funcionalidad atribuida, el Trabajo Social responde tanto a las demandas del capital como a las de los trabajadores; participa y refuerza tanto los mecanismos de la explotación de trabajo como, y por la misma actividad, da respuestas a las necesidades de los trabajadores. La intervención profesional participa de la reproducción de esos intereses sociales antagónicos.

"Es importante destacar este movimiento de la práctica profesional como producto de la historia y de los agentes que a ésta se dedican y que disponen de una autonomía relativa en la construcción de respuestas repetitivas o innovadoras frente a las demandas que le son históricamente presentadas (...) El reconocimiento de la historicidad de la profesión implica considerar el trabajo profesional como una práctica en proceso, en constante transformación; hecho éste que deriva

\footnotetext{
${ }^{15}$ IAMAMOTO, M. Servicio Social y División del trabajo. São Paulo, Cortez, 1997, pp. 91-92.

${ }^{16}$ Los servicios sociales conquistados por los trabajadores, funcionan contradictoriamente como conquistas históricas del movimiento de los trabajadores y, al mismo tiempo, como legitimadores del orden monopolista, puesto que los trabajadores comienzan a reconocerse en ese Estado que los ejecuta.
} 


\section{Ramiro Dulcich}

fundamentalmente de las modificaciones sucedidas en las formas de expresión y en la profundización de las contradicciones sociales en momentos y contextos históricos determinados"17.

En otro orden de cosas, y como ya fue marcado, a partir del reconocimiento e internalización de la "cuestión social" por el orden monopolista se desarrolla una tendencia a eclipsar ideológicamente las raíces de la misma; de esta forma, para poder abordarla en sus manifestaciones y exteriorizaciones, es fragmentada en una variedad infinita de "problemáticas sociales" que, consecuentemente, reclamaran ser abordadas por una variedad de actividades profesionales específicamente capacitadas para darles respuestas. Así, y como resultado tendencial, la "cuestión social" es despolitizada y retirada de la óptica de la lucha de clases. Este proceso es complementado y reforzado a través de la individualización de los problemas sociales, cuyo derivado coherente es la modalidad de enfrentamiento a las refracciones de la "cuestión social" vía estrategias de ajuste de la personalidad (Netto, 1992).

Por otro lado, y contradictoriamente, la intervención sistemática del Estado sobre la "cuestión social", y en función del capital monopolista, como ya dijimos, no se realiza lineal ni mecánicamente. Su procesamiento puede señalar conquistas parciales y significativas para la clase trabajadora (Netto, 1992). En las letras de este autor:

"La madurez política del proletariado y de sus organizaciones de clase, tiene uno de sus indicadores en la comprensión del potencial contradictorio de las políticas sociales"18.

Por todo esto, podemos decir que el Trabajo Social como profesión encuentra su funcionalidad social en el tratamiento de un conjunto de dificultades crecientes que el capital contradictoriamente genera y enfrenta al reproducirse. Es una profesión creada para intervenir en la construcción de un equilibrio, siempre tenso, entre los intereses -en última instancia, antagónicos- del capital y del trabajo. A esta profesión, así como a otras, se le demanda intervenir sobre aquel conjunto de condiciones necesarias para la expansión del capital- referentes a la construcción de bases político-económicas y de legitimidad del régimen social. Trayendo a lamamoto como subsidio fundamental:

“...la consolidación del Trabajo Social como institución tiene que ver con la ampliación del Estado, en el sentido de 'creación de brazos que avanzan al interior de la sociedad civil"19.

El ejercicio profesional se desenvuelve en relación con las condiciones de vida de las poblaciones que viven de la venta de su fuerza de trabajo, interviniendo sobre dichas condiciones en la búsqueda del mejoramiento de las mismas. De esta forma, se configura como una profesión integrada al proceso de creación de

${ }^{17}$ IAMAMOTO, M. Op. cit., p. XXIX.

${ }^{18}$ NETTO, J. P. Capitalismo Monopolista e Serviço Social. São Paulo, Cortez, 1992, p. 30.

${ }^{19}$ IAMAMOTO, M. Op. cit., p. XXVIII. 
condiciones indispensables al funcionamiento de la fuerza de trabajo como tal y, por esta mediación, de las condiciones necesarias a la extracción de plusvalía, medular para la acumulación del capital. En suma, es una profesión que interviene, junto con otras profesiones afines, sobre un conjunto de condiciones (materiales, ideológicas, políticas, organizativas, etc.) que son indispensables a la reproducción de las relaciones sociales propias del orden del capital.

El Trabajo Social interviene especialmente sobre las condiciones de vida de las clases trabajadoras, como una forma de anticiparse a los conflictos que por ella puedan poner en peligro el orden social ${ }^{20}$. Se le demanda, más específicamente, intervenir en el proceso de reproducción de la clase trabajadora, por la vía de la ejecución de servicios sociales. Estos dos momentos o niveles de la intervención profesional (uno mas vinculado a lo económico y otro más político) son complementarios y, justamente por eso, se potencian mutuamente. Con palabras de lamamoto:

"El Servicio Social surge como uno de los mecanismos utilizados por la clase dominante para el ejercicio de su poder en la sociedad, instrumento este que debe modificarse constantemente según las diferentes características asumidas por la lucha de clases (...) aparece como una alternativa a las acciones caritativas tradicionales, dispersas, en la búsqueda de atribuirle una 'nueva racionalidad' y mayor eficacia en el enfrentamiento de la 'cuestión social"'121.

Desde estas coordenadas, pensar la génesis del Trabajo Social desde una perspectiva crítico-dialéctica significa comprender su particularidad como portadora de elementos de continuidad y de ruptura, con respecto a las formas anteriores de intervención sobre la "cuestión social" (Netto, 1992). Las continuidades quedan evidenciadas cuando se analiza el tipo de intervención que el Trabajo Social ejerció desde su emergencia como profesión. Esto es, la modalidad técnico-operativa de intervención no sufrió demasiadas variaciones si se la compara con las formas de caridad y filantropía tradicionales. No obstante, las rupturas son claramente registradas en la nueva funcionalidad ocupada por el Trabajo Social profesionalizado; esto quiere decir que, por más que los profesionales tengan la representación de estar actuando con autonomía, realizando valores propios y de acuerdo con su voluntad, en verdad estos se encuadran en actividades interventivas cuya dinámica, organización, recursos y objetivos son determinados fuera de su control.

El proceso de profesionalización del Trabajo Social significa, elementalmente, que su funcionalidad social ahora es impuesta por organismos e instancias externas, con criterios muy distintos a los que regían el ejercicio de las llamadas proto-formas del Trabajo Social (Netto, 1992).

Podemos concluir entonces, en que la práctica profesional del Trabajo Social se encuentra tensionada por los intereses divergentes de las clases sociales; el ejercicio profesional se ve atravesado por las demandas contradictorias de éstas. Si los profesionales del Trabajo Social, o al menos un segmento de ellos, asumen

\footnotetext{
${ }^{20}$ Es muy interesante en este sentido, la idea de Netto (1992) sobre lo que llama «anticipaciones estratégicas» del capital; el cuidado allí debe ser puesto en no perder de vista la comprensión dialéctica que este autor hace de dicho proceso, donde la dinámica del conflicto social de clases no pierde centralidad.

${ }^{21}$ IAMAMOTO, M. Op. cit., p. 92.
} 


\section{Ramiro Dulcich}

como propios los intereses de las mayorías sociales víctimas de la lógica cada vez mas deshumanizante y bárbara del capital, la contradicción de depender profesionalmente de las estrategias de regulación social de la clase hegemónica y, a la vez, pretender acabar con ella, se hará presente como el gran dilema a superar, tanto en el terreno teórico-metodológico, en el de la intervención técnico-operativa de los profesionales y en el político organizativo.

\section{7 - El sincretismo del Trabajo Social}

Existe en la profesión, según Netto (1992), una dificultad reiterada para brindar tratamientos analíticos diferenciados al momento teórico del Trabajo Social y al momento práctico-profesional. Según este autor, la raíz de este problema está en la propia naturaleza socio-profesional; esto significa que, como producto de la carencia de un referencial teórico crítico dialéctico, el ejercicio profesional deriva en una práctica esencialmente sincrética.

Son tres, dirá este autor, los fundamentos objetivos que definen al Trabajo Social como portador de una estructura sincrética: a) el original universo de problemas al que se enfrenta, el cual exige respuestas profesionales efectivas; esto es, la llamada "cuestión social", más específicamente, sus refracciones societarias; b) el horizonte de su ejercicio profesional, esto es, la vida cotidiana; y, c) su modalidad especifica de intervención, esto es, la impronta interventiva de esta profesión.

La naturaleza difusa que asume la "cuestión social", que se constituye como un objeto de intervención polifacético capaz de recibir atención desde una gran variedad de prácticas profesionales, determina primariamente las formas de elaborar las respuestas profesionales ${ }^{22}$. La "cuestión social" se constituye como una multiplicidad problemática derivada y esencialmente determinada por la lógica de la sociedad capitalista madura. Justamente por esta configuración atomizada de las refracciones sociales de la "cuestión social" es posible enfrentar sus aspectos fenoménicos por medio de estrategias selectivas y / o simultaneas, o sea, es por la propia forma pulverizada y difusa en que la "cuestión social" se expresa, la multiformidad de su configuración, que se torna posible pensar su enfrentamiento a partir de intervenciones sectoriales, organizadas en una variedad compleja de prácticas profesionales específicas. Son las características propias del objeto de nuestra intervención (las manifestaciones pulverizadas de la "cuestión social), las que incitan a concebirlas aisladas unas de otras, desconectadas, en sí mismas, fomentando una intervención que reproduce dicha apariencia. Con las palabras de Netto,

\footnotetext{
${ }^{22}$ Se hace necesario aclarar que la utilización de la noción de determinación no designa (como muchos tratamientos superficialmente «críticos» vienen intentando instalar en el sentido común teórico) aquél movimiento unilateral que anula la contradicción. Por el contrario, desde una perspectiva crítico dialéctica, determinaciones son siempre resultados parciales de procesos dinámico-contradictorios, donde la síntesis nunca es acabada, ni pre-determinada en el proceso. Esta es, más bien, una resultante histórica que expresa el predominio de las tendencias más potentes al interior de tal proceso, pero estas no se presentan sino combinadas, sintetizadas con la multiplicidad de tendencias menos significativas que participaron de tal movimiento. Hablamos de determinaciones como mediaciones que efectivizan el movimiento, la dinámica contradictoria; como nexos causales que producen, expresan y explican lo real.
} 
"Se verifica, por lo tanto, que la problemática que demanda la intervención operativa del asistente social se presenta, en sí misma, como un conjunto sincrético; su fenomeneidad es el sincretismo, dejando en las sombras la estructura profunda de aquella que es la categoría ontológica central de la propia realidad social, la totalidad"23.

En segundo lugar, y colaborando en la definición de la estructura sincrética de nuestra profesión, no puede perderse de vista que el horizonte real donde ésta se efectiviza es la vida cotidiana. Esto significa que sus intervenciones técnicas e ideológicas se inscriben en el ambiente caótico y "heterogéneo" de lo cotidiano; aquello que Karel Kosik califica como pseudo-concreticidad. Según el análisis de Netto, "la funcionalidad histórica del Servicio Social (aunque no exclusiva de éste) aparece definida precisamente como una tecnología de organización de los componentes heterogéneos de la cotidianeidad de grupos sociales determinados, para resituarlos en el ámbito de esa misma estructura de lo cotidiano"24.

Por otro lado, y consolidando este sincretismo profesional, se destaca la modalidad específica de intervención de los Trabajadores Sociales, caracterizada por Netto como afectada por una "saturación de sus funciones ejecutivas"25. Seria esta "naturaleza" interventiva del Trabajo Social la que, conjugada perfectamente con la "naturaleza" sincrética de la materia sobre la cual trabaja, o sea, las múltiples refracciones sociales de la "cuestión social", redundaría en una práctica profesional estructuralmente sincrética.

Así, al mismo tiempo que se procede a legitimar el ordenamiento sectorial del enfrentamiento a la "cuestión social" - lo que implica reforzar la ilusión de que el tratamiento de sus refracciones sólo puede limitarse a la superficie del fenómeno: las problemáticas sociales-, también se consolida el rasgo eminentemente interventivo de la profesión, y su peculiaridad y destreza pasa a estar determinada por la eficacia creciente en la manipulación de variables empíricas, en el nivel de la vida cotidiana de las poblaciones que son "víctimas" de las refracciones sociales de la "cuestión social" del capitalismo maduro.

Por esto, esta profesión demandará conocimientos que sean directamente instrumentalizables, al mismo tiempo que absorberá todos los análisis y experiencias que puedan servirles para la modificación de aspectos inmediatamente empíricos del cotidiano, esto es, instrumentos teóricos y empíricos que refuercen su eficacia técnico-operativa. De esta forma, la tendencia a la incorporación ecléctica de conocimientos e instrumental técnico-operativo se afirma como una peculiaridad en la génesis del Trabajo Social tradicional. Esta peculiaridad ha sido denunciada y enfrentada críticamente, aunque esta muy lejos aún de ser erradicada de la intervención y formación de los profesionales de Trabajo Social.

El análisis sobre el cual nos estamos basando relaciona la estructura sincrética del Trabajo Social a su peculiaridad operacional, en tanto práctica sin soporte en una concepción teórico-social con matriz en el pensamiento crítico-dialéctico.

\footnotetext{
${ }^{23}$ NETTO, J. P. Capitalismo Monopolista e Serviço Social Op. cit., p. 21.

${ }^{24} \mathrm{Ibidem}$. El autor señala a modo de ejemplos al disciplinamiento de la familia trabajadora, la organización de los presupuestos familiares, la re-conducción de normas de conductas transgresoras, procesos de re-socialización, etc. (Netto, 1992: 92).

${ }^{25}$ Ibidem.
} 


\section{Ramiro Dulcich}

Trayendo una vez más a Netto:

“...la inmersión del aparato estatal burgués en el enfrentamiento de esas refracciones, por la vía privilegiada (pero nunca exclusiva) de las políticas sociales, no puede tener como objetivo su resolución (...) su naturaleza de partícipe en el juego económico, connatural a su esencia de clase, obligatoriamente le impide ir más allá de regulaciones que re-ecuacionen las condiciones, sectoriales y globales, adecuadas a la reproducción de las relaciones sociales burguesas - inmediatamente, su intervención tiende a resituar, sobre bases ampliadas, las refracciones de la 'cuestión social', pero nunca a promover su reversión (...) [se] tiende a conformar una cronificación de las refracciones de la 'cuestión social'"26.

Son trazos resultantes del propio sincretismo de la práctica profesional tanto el sistemático intento e imposibilidad de delimitar su especificidad como profesión, así como la "aparente polifuncionalidad" de su ejercicio.

"Múltiples vectores convergen para la práctica sincrética: las condiciones de intervención determinadas por las refracciones de la "cuestión social"; el referencial de las ciencias sociales gestadas en la razón tornada miserable; la continuidad, erguido el Trabajo Social como profesión, de las expectativas típicas que envolvían a sus proto-formas; la inserción peculiar en la división social (y técnica) del trabajo, etc.. La práctica sincrética se configura en el marco de la inmediación y de la pragmática constitutivas de la intervención que tiene como horizonte el espacio de lo cotidiano (...) Como su eficacia no depende de las exigencias de rigor y congruencia, esta práctica traslada al complejo profesional el sincretismo en ella privilegiado.

Si originalmente el sincretismo permea la práctica profesional del Trabajo Social como derivación de las condiciones (histórico-sociales e teórico-ideológicas) de su emergencia, consolidado el Trabajo Social como profesión la dinámica pasa a tener como soporte su práctica: su peculiar sincretismo práctico condiciona largamente el sincretismo de sus representaciones"27.

\section{8 - Algunas conclusiones parciales}

El recorrido que intentamos en este trabajo no tiene otra finalidad que indagar sobre la legalidad del funcionamiento de la sociedad contemporánea, procurando situar allí la emergencia y consolidación institucional de nuestra profesión, entendiendo esto como un momento fundamental, esencial para la elaboración crítica de los límites actuales que nuestras intervenciones encuentran, como también para la formulación de posibles salidas o alternativas.

Por otro lado, estamos convencidos de que este punto de partida genérico, que se preocupa por entender los fenómenos en sus determinaciones y desde el principio de la totalidad, se torna ineludible a la hora de pensar estrategias que permitan cualificar nuestra profesión, consolidarla en el terreno teórico metodológico, de la investigación, así como fortalecer la organización gremial de sus entidades de

${ }^{26}$ NETTO, J. P. Capitalismo Monopolista e Serviço Social Op. cit., p. 98.

${ }^{27}$ NETTO, J. P. Capitalismo Monopolista e Serviço Social. Op. cit., p. 103. 


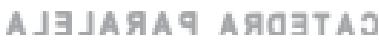

formación y de intervención profesional, buscado establecer interlocuciones con otras áreas del conocimiento. Para todo esto, nos es fundamental contar con un marco teórico sólido que explique aquello que fuimos, que somos y que proyectamos ser como colectivo profesional. Por esto, es fundamental fomentar e incentivar la crítica social en nuestro campo, como precondición para la comprensión de la complejidad de lo real al cual nos enfrentamos cotidianamente, que insiste en aparecer fragmentado, con sus fenómenos aparentemente desconectados unos de los otros.

Recuperar la perspectiva metodológica de la totalidad para hacer frente a la explicación de lo real y dotar de sentido nuestras intervenciones, se torna imperioso. Sabemos que el camino es largo y en parte desconocido, y que lo hecho es todavía insuficiente al lado del desafío que tenemos por delante. No hay mas remedio que caminar y aprender en la marcha, siempre atentos a las limitaciones que las generaciones pasadas encontraron, enfrentaron y elaboraron; debemos tomar eso como lecciones.

Nos mueve la convicción de que un Trabajo Social críticamente agudo y éticamente comprometido con valores humanistas y democráticos es posible, así como necesario es que sea construido colectivamente, teniendo como horizonte su contribución, desde su lugar, reconociendo claramente sus límites y posibilidades, al proceso de emancipación social que cada día se torna mas humanamente urgente.

\section{Bibliografía}

BORGIANNI E.; GUERRA Y.; MOÑTAÑO C. (Orgs.). Servicio Social Critico: Hacia la construcción del nuevo proyecto ético-político profesional. São Paulo, Cortes Editora, 2003.

COUTINHO, C. N. Marxismo e Política. A dualidade de poderes e outros ensaios. São Paulo, Cortez, 1996.

IAMAMOTO, M.; CARVALHO, R. Relações sociais e Serviço Social no Brasil. Esboço de uma interpretação histórico-metodologica. São Paulo, Cortez-Celats, 1986.

IAMAMOTO, M. Servicio Social y División del trabajo. São Paulo, Cortez, 1997. KOSIK, K. Dialéctica de lo concreto. México, Grijalbo, 1984.

LUKACS, G. Estética 1; Vol. 3: La peculiaridad de lo estético. Barcelona, Grijalbo, 1982.

MANDEL, E. El capital: cien años de controversias en torno de la obra de Karl Marx. México, Siglo XXI, 1998.

MARX, K. El Capital. Tomo I. La Habana, Editorial de Ciencias Sociales, 1981. . El Capital. Tomo III. La Habana, Editorial de Ciencias Sociales, 1980. 


\section{Ramiro Dulcich}

MARX, C.; ENGELS, F. A ideología alema: Feuerbach. São Paulo, Hucitec, 1993.

MÉSZÁROS, I. Para além do capital: Rumo a uma teoria da transição. Brasil, Boitempo-UNICAMP, 2002.

NETTO, J. P. Capitalismo Monopolista e Serviço Social. São Paulo, Cortez, 1992.

. Marxismo Impenitente. Contribuição a historia das idéias marxistas. São Paulo, Cortez, 2003.

ROSDOLSKI, R: Génesis y estructura de El capital de Marx (estudios sobre los Grundrisse). México, Siglo XXI, 1989. 